\title{
A ESTRUTURA
}

PASSIVA

NUM CORPUS DE

AQUISIÇÃO

\section{LA ESTRUCTURA PASIVA EN UN CORPUS DE ADQUISICIÓN}

\author{
THE PASSIVE STRUCTURE IN AN ACQUISITION CORPUS
}

\author{
Antónia Estrela* \\ Centro de Linguística da Universidade Nova de Lisboa \\ Escola Superior de Educação de Lisboa
}

\begin{abstract}
RESUMO: O objetivo deste trabalho é descrever a estrutura passiva num corpus de aquisição, contabilizando e tipificando as passivas que surgem na fala espontânea das crianças e dos adultos que com elas interagem. Dado que, no campo da aquisição da linguagem, vários estudos apontam para eventuais atrasos na aquisição da passiva, pretendeu-se verificar se, em português europeu, essa estrutura surgia tardiamente e qual o tipo de passiva a emergir primeiramente. Feito o levantamento de todas as passivas presentes no corpus, procedeu-se à sua análise. Os dados mostram que as crianças produzem passivas estativas e só depois passivas eventivas e resultativas. O tipo de passivas que as crianças produzem mais cedo e em maior quantidade é aquele que é mais produzido pelos adultos em interação com elas, ou seja, a passiva estativa. Destaca-se ainda a idade bastante precoce em que estas construções começam a ser produzidas (antes dos dois/três anos).
\end{abstract}

PALAVRAS-CHAVE: Estrutura passiva. Aquisição. Corpus.

RESUMEN: Este trabajo tiene como objetivo describir la estructura pasiva en un corpus de adquisición, contando y tipificando las pasivas que surgen en el habla espontánea de los niños y adultos en la interacción. Teniendo en cuenta que, en el campo de la adquisición del lenguaje, varios estudios apuntan a posibles retrasos en la adquisición de pasiva, se pretendía determinar si, en el portugués europeo, esta estructura llegó tarde y qué tipo de pasiva surge primero. Después de hacer un estudio de todas las pasivas presentes en el corpus, se procedió al análisis. Los datos muestran que los niños primero producen pasivas estativas y después eventivas y resultativas. De hecho, pasivas estativas son las que producen los niños antes y en cantidad más grande. Esta es exactamente la misma que se produce por la mayoría de los adultos que interactúan con ellos. Las pasivas estativas emergen muy temprano, antes de los dos/ tres años.

PALABRAS CLAVE: Estructura pasiva. Adquisición. Corpus.

ABSTRACT: The aim of this paper is to describe the passive structure through an acquisition corpus, accounting and typifying the passives that arise in children's and adults' spontaneous speeches as they interact with each other. Given that in the field of language acquisition several studies point out to eventual delays in the passive acquisition, we tried to verify if, in the European Portuguese, this structure would emerge late, and what would the passive type to first emerge. Once the collection of all the passive present in

*Doutorada em Linguística pela Faculdade de Ciências Sociais e Humanas da Universidade Nova de Lisboa e professora na Escola Superior de Educaçãode Lisboa. E-mail: antoniaestrela@gmail.com. 
the corpus was made, we started the analysis. The data collected show that children produce passive stative, and only then they produce eventive and resultative passives. The type of passives children produce earlier and in a larger scale is the one that is produced more often by adults who interact with them. In other words, the stative passive. We can also highlight the very early age in which these constructions start to be produced (before they are two or three years old).

KEYWORDS: Passive structure. Acquisition. Corpus.

\section{INTRODUÇÃO}

O estudo da aquisição da estrutura passiva tem sido feito para diversas línguas, assumindo-se diferentes campos teóricos, diversas metodologias e obtendo-se, também, resultados distintos. No entanto, no que diz respeito ao Português Europeu, são muito poucos os trabalhos que versam sobre a aquisição desta estrutura. Por esse motivo, este é o tema em discussão ${ }^{1}$.

Assim, pretende-se descrever a estrutura passiva num corpus de aquisição (SANTOS, 2006), tendo em conta não só a quantidade de ocorrências, como também a sua tipologia. Este corpus contém fala produzida por crianças e pelos adultos que com elas interagem, tendo sido transcrito de acordo com o sistema CHILDES (Child Language Data Exchange System), usando-se o software CLAN (MACWHINNEY, 2000). Inclui cerca de 52 horas de interação entre criança e adulto, havendo 18.492 produções de crianças. O corpus de Santos (2006) permitirá, assim, estudar a fala espontânea de três crianças, ainda numa fase precoce de aquisição da linguagem.

Numa primeira parte deste trabalho, apresentamos a tipologia que adotamos no que diz respeito à tipificação de passivas; em seguida, mostramos alguns estudos sobre aquisição de passivas em outras línguas; na quarta seção, descrevemos e analisamos a ocorrência de passivas no corpus de Santos (2006); e concluímos com algumas notas finais.

\section{A TIPOLOGIA TRIPARTIDA DE PASSIVAS}

Duarte (2013), a partir do trabalho de Embick (2004), propõe uma tipologia tripartida de construções passivas (passiva eventiva, passiva resultativa e passiva estativa), mencionando argumentos que validem tal proposta. Os exemplos seguintes constituem uma passiva eventiva, uma passiva resultativa e uma passiva estativa, respetivamente ${ }^{2}$ :

1. O exemplo foi corrigido por um falante nativo.

2. O exemplo ficou corrigido (depois de ter sido revisto).

3. O exemplo está correcto.

Um aspeto que ajuda na distinção entre particípios eventivos e resultativos, por um lado, e estativos, por outro, diz respeito à componente eventiva presente nos dois primeiros, mas ausente nos últimos. Para além disso, a componente agentiva caracteriza somente os particípios eventivos. Estes são os únicos que podem ocorrer, em português, com agente da passiva (cf. 4a), com advérbios orientados para o agente (cf. 4b), com sintagmas preposicionais instrumentais (cf. 4c). Para além disso, podem controlar o sujeito nulo de orações finais (cf. $4 \mathrm{~d}$ ). Os exemplos seguintes mostram esses contrastes:

4. a. O exemplo foi corrigido por um falante nativo.

b. O exemplo foi corrigido propositadamente (pelo autor).

c. O exemplo foi corrigido com tinta azul.

\footnotetext{
${ }^{1}$ Em Estrela (2013), estudamos a aquisição da passiva em português europeu, recorrendo a vários estudos experimentais, cujo objetivo consistia em perceber como se processa a aquisição de diversos tipos de passivas com diferentes tipos de verbos. No atual trabalho, apresentamos apenas a análise com base num corpus de aquisição.

${ }^{2}$ Os exemplos (1) a (5) são de Duarte e Oliveira (2010, p. 401-402).
} 
d. O exemplo foi corrigido por [um falante nativo $]_{\mathrm{i}}$ para $[-]_{\mathrm{i}}$ mostrar a pronúncia correcta.

Já os exemplos em 5) são todos agramaticais ou pouco aceitáveis na medida em que as passivas resultativas são incompatíveis com os contextos em que há marcas de agentividade. $\mathrm{O}$ mesmo acontece com as estativas.

5. a. ${ }^{\star} \mathrm{O}$ exemplo ficou corrigido por um falante nativo.

b. ${ }^{\star}$ O exemplo ficou corrigido propositadamente (pelo autor).

c. ?O exemplo ficou corrigido com tinta azul.

d. ${ }^{\star} \mathrm{O}$ exemplo ficou corrigido para mostrar a pronúncia correcta.

No quadro seguinte, apresentamos um resumo dos contextos que poderão ser usados para aferir se determinada construção exibe uma estrutura com particípio eventivo, resultativo ou estativo.

Quadro1: O comportamento de particípios eventivos, resultativos e estativos em Português

\begin{tabular}{c|c|c|c} 
& Eventivo & Resultativo & Estativo \\
\hline $\begin{array}{c}\text { Sintagmas preposicionais de valor } \\
\text { instrumental }\end{array}$ & $\checkmark$ & $*$ & $*$ \\
\hline Orações subordinadas finais & $\checkmark$ & $*$ & $*$ \\
\hline Complemento agente da passiva & $\checkmark$ & $*$ & $*$ \\
\hline Advérbios orientados para o agente & $\checkmark$ & $*$ & $*$
\end{tabular}

Fonte: Estrela (2013), elaborado a partir de Duarte e Oliveira (2010)

Os particípios resultativos constroem-se tipicamente com ficar. Este verbo marca o fim de um evento e o início de um estado resultativo. Assim, as passivas resultativas assinalam não só o estado resultante como ainda a fronteira da passagem a esse estado, pelo que admitem a expressão em $x$ tempo, que serve para medir o tempo que o processo demora até que seja atingido o estado resultante (DUARTE, 2013):

6. O jantar fica servido em 5 minutos.

Por sua vez, as passivas estativas descrevem situações estativas, mas não incluem a componente da fronteira da passagem ao estado, como se pode observar nos exemplos 7 e 8 :

7. O autor é reconhecido mundialmente.

8. A professora está desorientada.

Os exemplos acima mostram a distinção das passivas estativas relativamente às eventivas e às resultativas, uma vez que a seleção do verbo auxiliar é sensível ao tipo de predicado: com predicados estáveis (que denotam propriedades estáveis dos indivíduos), utilizase o verbo ser (cf. 7), enquanto com predicados episódicos (que denotam propriedades transitórias dos indivíduos) se utiliza o verbo estar (cf. 8) (DUARTE, 2013). 


\section{ALGUNS ESTUDOS SOBRE A AQUISIÇÃO DE PASSIVAS}

Para a análise da aquisição de estruturas passivas, há muitos estudos que recorrem a diferentes técnicas experimentais, mas também a dados de corpora. Uma questão a considerar quando se trabalha com dados reais diz respeito à eventual ausência ou escassez de certas estruturas no corpus. As implicações desse fato têm de ser analisadas cuidadosamente. A sua omissão poderá ser justificada pelo desconhecimento da estrutura em causa, por exemplo, ou pela sua inadequação no contexto, ou ainda pela simples preferência por outra estrutura, pelo que não se poderá generalizar a ideia de que, se a construção não for produzida, tal significará que a criança a desconhece. De qualquer modo, parece-nos que o estudo baseado em dados de corpora é precioso, pelas pistas e resultados que estes podem fornecer.

Em Estrela (2013), demos conta de quatro estudos experimentais que visavam aferir a partir de quando as crianças compreendem a passiva, para além de analisarmos um corpus de aquisição. Como tal, consideramos importante ver como alguns autores exploraram a aquisição da passiva tendo por base dados de corpora e é esse o motivo que explica a escolha das referências seguintes - em particular.

Alguns estudos sobre passivas na fala dirigida a crianças revelam-se pertinentes. Gordon e Chafetz (1990), por exemplo, investigaram a quantidade de passivas num corpus desse tipo. A análise de 86.655 linhas de fala dirigida a três crianças mostra a existência de 313 passivas. Em média, os adultos produzem 36 passivas por mil enunciados (utterances), portanto, 0,36\% de todo o input. As passivas mais comuns foram passivas curtas com verbos agentivos, tendo sido apenas produzidas quatro passivas longas. As passivas com verbos não agentivos também foram muito raramente produzidas (GORDON; CHAFETZ, 1990). Os autores identificaram a presença de $63 \%$ de passivas adjetivais e $37 \%$ de passivas verbais. Os exemplos abaixo representam, respetivamente, os dois tipos de passiva (GORDON; CHAFETZ, 1990, p. 233)

9. The toy was broken to prove a point.

10. The toy is broken.

Destes dados, podemos retirar a ideia de que as crianças recebem poucos exemplos de passivas no input a que estão expostas.

Recorrendo igualmente a dados de corpora, Kline e Demuth (2010) defendem que, na língua sesotho, uma alta frequência de passivas no input promove uma aprendizagem implícita rápida e facilita a compreensão de passivas. Esta abordagem implica que a aquisição da linguagem ocorre de modo diretamente relacionado com ordem, input e "procedural memory". Há, no entanto, autores que rebatem esta proposta (CRAWFORD, 2012).

Crawford (2012) critica a aparente facilidade que as crianças falantes de sesotho revelaram com passivas, argumentando que não foram realizados estudos experimentais que corroborassem os dados fornecidos pela fala espontânea das crianças. Para colmatar essa falta, a autora levou a cabo um estudo de compreensão de frases ativas, passivas longas e passivas curtas, com 11 crianças (5;06;0). Os dados revelam maiores dificuldades com a passiva longa do que com a ativa, o que contraria a explicação da aquisição com base na frequência de frases passivas no input. Neste estudo, a autora não terá reunido as condições de sucesso de que falam O’Brien et al. (2006) pelo que os seus dados também poderão ser criticados, não obstante a existência de outros estudos que revelam que tais condições não são tão determinantes, como se chegou a pensar, para o bom desempenho das crianças na tarefa.

Israel, Johnson e Brooks (2000) analisaram a fala de sete crianças, disponível no corpus CHILDES e identificaram três períodos no desenvolvimento da passiva: as crianças usam primeiramente a passiva estativa, depois recorrem aos particípios passivos em contextos ambíguos (em que podem ser interpretados como estativos ou eventivos) e, por fim, usam os particípios para denotar eventos. A função da passiva muda ao longo do tempo, passando de estativa (descrevendo estados) para eventiva (descrevendo eventos). A partir do conhecimento da passiva estativa constroem a passiva eventiva. Para os autores, os particípios estativos são adquiridos em primeiro lugar, porque geralmente são produzidos no próprio momento em que a situação ocorrida é verbalizada e descrita. 
Reconhecendo-se a importância dos dados fornecidos por corpora, importa, não obstante, referir a relevância de se realizarem, sempre que possível, estudos experimentais que corroborem os dados fornecidos pela fala espontânea.

\section{A PASSIVA NO CORPUS DE SANTOS (2006)}

O corpus que servirá de base à nossa análise é o de Santos (2006), um corpus de fala de crianças e de fala dirigida a crianças, que está transcrito de acordo com o sistema CHILDES. Os dados foram recolhidos com recurso ao vídeo e correspondem a uma interação adulto-criança numa ambiente natural, ou seja, as crianças foram filmadas nas suas próprias casas, em interação com as suas famílias (sobretudo com as mães). As sessões foram semanais, no entanto, foi selecionada para transcrição uma gravação por mês. O corpus tem as características indicadas no quadro $2^{3}$ :

\begin{tabular}{c|c|c|c|c}
\multicolumn{5}{c}{ Quadro 2: Idades e produções das crianças representadas no corpus de Santos (2006) } \\
Criança & Idade & MLUw & Número de ficheiros & $\begin{array}{c}\text { Número de enunciados } \\
\text { da criança }\end{array}$ \\
\hline INI & $1 ; 6.6-3 ; 11.12$ & $1.527-3.815$ & 21 & 6,591 \\
\hline TOM & $1 ; 6.18-2 ; 9.7$ & $1.286-2.954$ & 16 & 6,800 \\
\hline INM & $1 ; 5.9-2 ; 7.24$ & $1.315-2.370$ & 15 & 5,101
\end{tabular}

Fonte: Santos (2006)

A partir da análise deste corpus, pretende-se discutir, essencialmente, se existe uma ordem na emergência dos três tipos de passivas e em que medida os dados do input fornecem um contributo para determinar não só essa ordem, mas também o seu número de ocorrências. Neste sentido, a possibilidade da existência de princípios formais inatos pode fornecer pistas para explicar estes dados. Sintaticamente, a própria passiva estativa é aquela que apresenta uma estrutura menos complexa: seleciona tipicamente como complemento uma única projeção funcional. Além disso, semanticamente, é o único tipo de passiva que não acarreta nem eventividade nem agentividade.

Por sua vez, o impacto do input também não pode ser ignorado, uma vez que o número elevado de passivas estativas produzidas pelas crianças (face às passivas eventivas e resultativas) pode ser, por exemplo, um reflexo da quantidade desse tipo de passivas presentes na fala do adulto. Um corpus de aquisição que disponibilize a fala dos adultos que interagem com as crianças será valioso pela análise global que pode oferecer. O corpus em análise apresenta os dados de interação adulto(s)-criança, o que nos permite estudar, para o português europeu, não só a existência de estruturas passivas produzidas pelas crianças, como também a existência dessa estrutura na fala a elas dirigida.

\subsection{METODOLOGIA}

Para esta análise, todo o corpus foi considerado, tendo sido feito o levantamento de todos os enunciados que continham estruturas passivas, não só das produções das crianças, como também da fala dos adultos. O intuito é, também, verificar se os dados dos adultos se relacionam de alguma forma com os das crianças, no que diz respeito à estrutura passiva.

Como na altura em que foi feito o estudo o corpus não estava anotado com informação morfossintática, não foi feito o levantamento de todos os lemas dos verbos que ocorreram na voz ativa. Fez-se o levantamento dos verbos que surgiram em construções passivas,

\footnotetext{
${ }^{3}$ Neste trabalho, utilizamos a primeira versão do corpus. Uma versão aumentada está disponível online: <http://childes.talkbank.org/data/Romance/Portuguese>.

${ }^{4}$ A medida geral mais comum para medir o desenvolvimento linguístico é o MLU (Mean Length of Utterance).
} 
tendo sido consideradas as construções de ser, estar e ficar, com particípios passados. Depois deste primeiro levantamento, foi feita uma nova seleção de construções, tendo em conta as suas propriedades.

\subsection{DADOS}

No que diz respeito aos dados, primeiramente, disponibilizamos os dados de cada criança, para depois fazermos uma comparação entre elas.

A tabela 1 mostra a quantidade de passivas produzidas pelas três crianças:

\begin{tabular}{c|c|c|c|c} 
& Eventivas & Resultativas & Estativas & TOTAL \\
\hline INM & 0 & 0 & 2 & 2 \\
\hline TOM & 1 & 1 & 22 & 24 \\
\hline INI & 1 & 2 & 41 & 44
\end{tabular}

Tabela 1: Número de passivas produzidas pelas três crianças

O gráfico 1 evidencia a diferença ao nível da quantidade de passivas eventivas, resultativas e estativas:

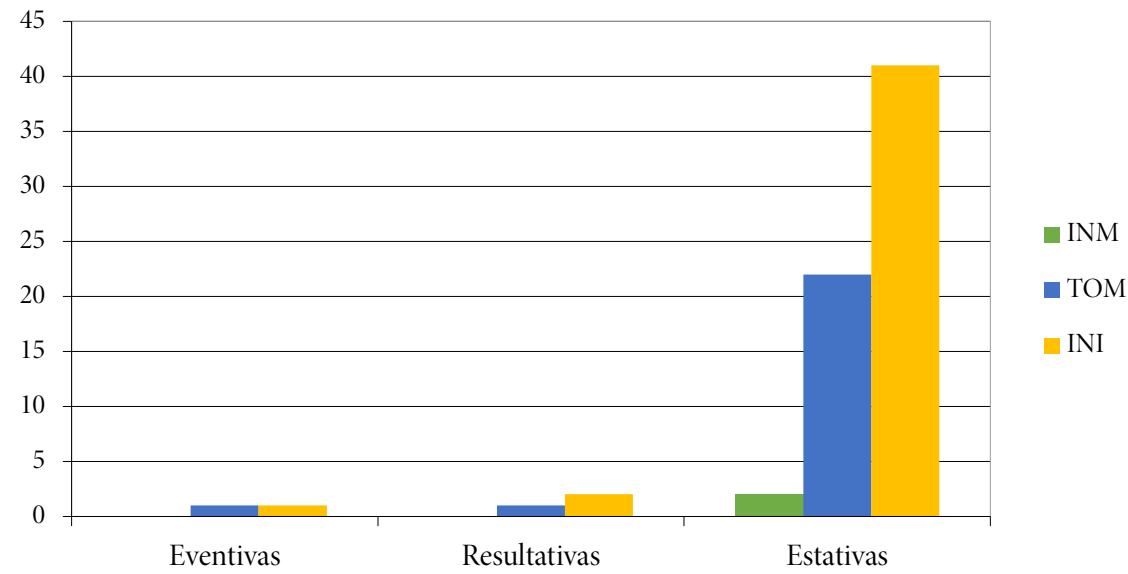

Gráfico 1: Número de passivas produzidas pelas três crianças

Uma das crianças (TOM) destaca-se pela precocidade com que produziu passivas estativas, comparativamente a outra criança, nomeadamente INM. Nas produções de TOM, surgiram os três tipos de passivas, tendo a passiva estativa sido produzida aos 1;9.14 (cf. exemplos 11 e 12), a eventiva aos 2;6.6 (cf. exemplo13) e a resultativa aos 2;9.7 (cf. exemplo 14):

11. a@ (a)pagada

12. (es)tá pa(r)tido.

13. $\quad+<\mathrm{xx}$ mas \# tem \# de se(r) \# lavado [?].

14. /] \# e depois \# eles ficam aqui pendu(r)adas \# e (de)pois comeu o osso. (2;9.7)

\footnotetext{
${ }^{5} \mathrm{O}$ primeiro número se refere a anos; o segundo a meses; e o terceiro a dias.
} 
Por sua vez, nas gravações referentes a INM, não se encontram registadas quaisquer passivas eventivas ou resultativas até aos dois anos e sete meses, idade quando da última sessão. Contudo, a criança produz duas passivas estativas, depois dos 2 anos, como mostram os exemplos seguintes:

15. a (I)nê(s) num [: não] (es)tá cansada. (2;0.14)

16. (es)tá limpinha? $(2 ; 5.23)$

No caso da INI, os registos mostram que a primeira estativa surge também depois dos 2 anos (cf. exemplo 17); a eventiva aos 3;4 meses (cf. exemplo 18) e a resultativa também a partir dos 3;7 (cf. exemplos 19 e 20).

\section{7. (es)tá est(r)agado. $(2 ; 2.1)$}

18. $\quad$ po(r)qu(e) isto \# foi filmad(o) $(3 ; 4.6)$

19. o pai ficava aqui metido. $(3 ; 7.29)$

20. ficavam molhad(o)s. $(3 ; 11.12)$

Ainda a partir dos dados apresentados, o que se nota é que, de início, as passivas estativas são as mais frequentes na fala produzida pelas crianças, surgindo as eventivas e as resultativas posteriormente e com uma baixa frequência. Vinte e uma das passivas estativas produzidas pela INI surgem depois dos três anos, o que explica a diferença dos dados em relação às restantes crianças, cujos registos não incidem sobre os três anos. Assim, tendo em conta o exemplo de INI, pode ver-se que, mesmo depois dos três anos, são as passivas estativas aquelas que têm mais expressão na fala das crianças. Ainda que tenha sido gravada até aos 3;11.12, INI apenas produziu uma passiva eventiva e duas resultativas, o que parece mostrar que estas passivas poderão tornar-se mais frequente numa idade posterior àquela que está aqui em causa.

O gráfico abaixo, relativo às idades em que as crianças produzem, pela primeira vez no corpus, determinado tipo de passiva, pode ajudar-nos a visualizar o caminho percorrido pelas crianças no que diz respeito à produção da construção em análise:

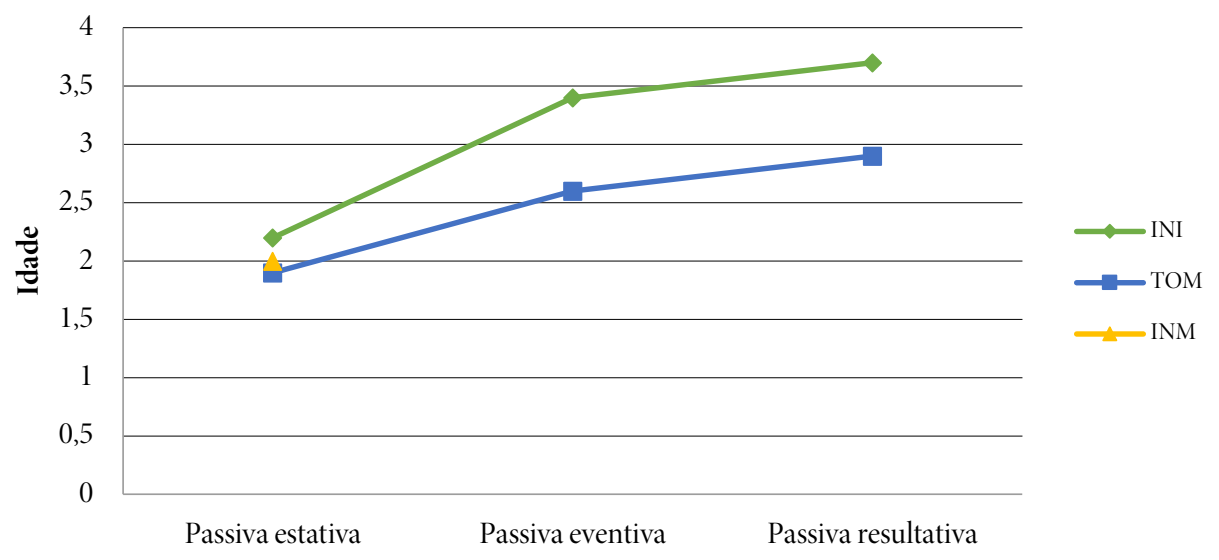

Gráfico 2: Idades das crianças aquando da produção de cada tipo de passiva

O que o Gráfico 2 mostra é que, tendo em conta as produções das três crianças, a passiva estativa surge entre os 1;9 e 2;2 anos; a passiva eventiva emerge entre os 2;6 e 3;4; e a resultativa entre os 2;9 e 3;7. Esta seria, portanto, a ordem de aquisição dos três tipos de passiva. A linha ascendente relativa às crianças que produziram os três tipos de passiva (INI e TOM) mostra que é com o avançar da idade que vão surgindo as diferentes construções.

Em relação aos verbos que surgiram nestas construções, as produções de TOM foram construídas com os seguintes verbos: 


\begin{tabular}{|c|c|c|c|}
\hline & estativa & eventiva & resultativa \\
\hline abrir & 1 & 0 & 0 \\
\hline acordar & 2 & 0 & 0 \\
\hline agarrar & 1 & 0 & 0 \\
\hline apagar & 1 & 0 & 0 \\
\hline assustar & 4 & 0 & 0 \\
\hline esconder & 6 & 0 & 0 \\
\hline estragar & 3 & 0 & 0 \\
\hline lavar & 0 & 1 & 0 \\
\hline molhar & 1 & 0 & 0 \\
\hline partir & 3 & 0 & 0 \\
\hline pendurar & 0 & 0 & 1 \\
\hline
\end{tabular}

Tabela 2: Identificação de verbos produzidos por TOM e respetiva quantidade

Na tabela 3, estão os verbos utilizados por INM:

\begin{tabular}{c|c} 
& estativa \\
\hline cansar & 1 \\
\hline limpar & 1
\end{tabular}

Tabela 3: Identificação de verbos produzidos por INM e respetiva quantidade

Na tabela 4, estão os verbos usados por INI:

\begin{tabular}{c|c|c|c} 
& estativa & eventiva & resultativa \\
\hline abrir & 2 & 0 & 0 \\
\hline apertar & 3 & 0 & 0 \\
\hline arrumar & 1 & 0 & 0 \\
\hline avariar & 3 & 0 & 0 \\
\hline complicar & 1 & 0 & 0 \\
\hline deitar & 1 & 0 & 0
\end{tabular}




\begin{tabular}{|c|c|c|c|}
\hline desapertar & 1 & 0 & 0 \\
\hline descalçar & 2 & 0 & 0 \\
\hline enfeitar & 1 & 0 & 0 \\
\hline esconder & 1 & 0 & 0 \\
\hline escrever & 2 & 0 & 0 \\
\hline estragar & 4 & 1 & 0 \\
\hline fechar & 2 & 0 & 0 \\
\hline ler & 2 & 0 & 0 \\
\hline meter & 0 & 0 & 1 \\
\hline molhar & 1 & 0 & 1 \\
\hline partir & 5 & 0 & 0 \\
\hline pendurar & 2 & 0 & 0 \\
\hline prender & 1 & 0 & 0 \\
\hline riscar & 1 & 0 & 0 \\
\hline sentar & 2 & 0 & 0 \\
\hline tapar & 3 & 0 & 0 \\
\hline
\end{tabular}

Tabela 4: Identificação de verbos produzidos por INI e respetiva quantidade

Os verbos usados nas produções das três crianças, como esconder, estragar, molhar, pendurar, limpar, dizem respeito, geralmente, ao contexto em que elas se encontram inseridas, ou seja, as crianças falam sobre algo que está presente no contexto e/ou que acabou de acontecer, como podemos ver no excerto abaixo (INI 2;8.23):

21. ${ }^{\star} \mathrm{MJF}^{6}$ : olha \# mas está aqui outra coisa também muito importante para eles.

${ }^{*} \mathrm{MJF}$ : o que é isto?

${ }^{\star}$ INI: uma [?] cadeiri(nha) [?].

${ }^{\star}$ MJF: uma cad $+/$.

${ }^{*}$ INI: a (ca)deiri(nh)a [?] <(es)tá pa(r)tida> [//] (es)tá pa(rtida).

Os dados relativos às produções das crianças podem ser comparados com a quantidade de passivas produzidas pelos adultos presentes nas diversas sessões. Se as crianças são mais produtivas em relação às passivas estativas, o mesmo se passa em relação aos dados dos adultos.

${ }^{6}$ Identificação do investigador que interage com a criança. 
Na verdade, também estes revelam uma clara preferência pela produção de passivas estativas, constituindo estas mais de $80 \%$ do total de passivas produzidas, como se pode constatar na tabela abaixo apresentada:

\begin{tabular}{c|c|c|c|c}
$\begin{array}{c}\text { Produção do(s) } \\
\text { adulto(s) que } \\
\text { acompanha(m) }\end{array}$ & Eventivas & Resultativas & Estativas & TOTAL \\
\hline INM & $5(4 \%)$ & $15(13 \%)$ & $96(83 \%)$ & 116 \\
\hline TOM & $3(3 \%)$ & $9(9 \%)$ & $86(88 \%)$ & 98 \\
\hline INI & $4(2 \%)$ & $7(5 \%)$ & $155(93 \%)$ & 166
\end{tabular}

Tabela 5: Número de passivas produzidas pelos adultos em interação com as crianças

A Tabela 5 apresenta os dados relativos aos enunciados que continham passivas que foram produzidos pelos adultos que acompanhavam as crianças durante as gravações e mostra claramente a diferença entre a quantidade de passivas eventivas, resultativas e estativas produzidas. Enquanto as duas primeiras não ultrapassam os 4\% e os 15\%, respectivamente, as passivas estativas são produzidas em maior número pelos adultos em interação com as crianças. Além disso, se estabelecermos uma comparação entre o número de passivas produzido por cada criança e o número de passivas que recebem do input, vemos que não há sempre uma relação direta entre os dados, ou seja, a criança que produz um número mais reduzido de passivas (INM) não é a que recebe menos passivas no input. Por outro lado, a criança que produz um número mais elevado de passivas (INI) é aquela cujo input tem disponíveis mais estruturas desse tipo. No entanto, esta observação poderá também estar relacionada, como já dissemos, com o fato de INI ser a única criança cujos registos incluem gravações para além dos três anos. A tabela 6 mostra a proporção de passivas produzidas e de passivas presentes no input dos adultos em interação com as crianças:

\begin{tabular}{c|c|c} 
& Passivas produzidas & Passivas no input \\
\hline INM & 2 & 116 \\
\hline TOM & 24 & 98 \\
\hline INI & 44 & 166
\end{tabular}

Tabela 6: Comparação entre passivas produzidas pelas crianças e passivas produzidas no input

Mais do que explicar a importância do input, o que nos interessa particularmente é a ordem de aquisição dos três tipos de passivas, o que discutiremos na seção seguinte deste trabalho. No entanto, podemos constatar que a discussão sobre a qualidade e quantidade do input tem merecido vários estudos ao longo dos anos. A título de exemplo, lembramos Lightfoot (1991), que advoga que a robustez dos dados não se relaciona com a frequência. Por outro lado, Yang (2004) prefere propor um modelo no qual a frequência de certos tipos de dados no input é relevante, sendo a Gramática Universal responsável por delimitar quais são esses dados.

No que diz respeito aos verbos que surgem nas produções dos adultos, alguns são verbos como desfazer, despentear, esconder e estragar. Tal como acontece com os verbos produzidos pelas crianças, a maior parte dos verbos usados diz respeito, geralmente, ao contexto em que se encontram inseridos os participantes, isto é, os adultos referem-se àquilo que está a acontecer no contexto em que se encontram. 


\subsection{DISCUSSÃO DOS DADOS}

Como sabemos, os dados de produção espontânea apresentam limitações, uma vez que é muito difícil, nessas situações, registar-se todas as construções que gostaríamos de estudar e com uma alta frequência. Tal não significa que a construção não seja efetivamente produzida; poderá acontecer, por exemplo, que não se tenha proporcionado o seu uso no contexto em análise.

Os dados da fala espontânea analisados permitiram-nos verificar que, tendo em conta a ordem de emergência dos diferentes tipos de passivas, poderemos assumir que as passivas estativas são as primeiras a ser produzidas pelas crianças, seguindo-se as eventivas e as resultativas.

Também Israel, Johnson e Brooks (2000) mostram que as primeiras passivas a ser produzidas pelas crianças são as estativas (adjetivais), passando apenas mais tarde as crianças a usar passivas eventivas. Para os autores, os particípios estativos são aprendidos porque geralmente produzidos no contexto a que dizem respeito. As passivas estativas parecem ser mais salientes para as crianças, pelo menos numa fase inicial de aquisição da linguagem.

No nosso estudo, verificamos que as crianças produziram particípios estativos desde cedo e só mais tarde (passado um período considerável, por vezes mais de um ano) começaram a produzir particípios com leitura eventiva. Além disso, é também de notar, em duas das três crianças, a semelhança na ordem de aquisição destas estruturas: primeiro surgem as estativas e só depois as passivas eventivas e resultativas.

Para explicar os dados encontrados, Israel, Johnson e Brooks (2000) defendem uma perspetiva construcionista, em que a criança, em vez de ativar princípios formais inatos, adquiriria a passiva através de um domínio gradual dos aspectos que a caracterizam, ao nível da forma e ao nível do significado. Parece-nos que esta base teórica não é suficientemente consistente para explicar, por si só, a emergência destes vários tipos de construções passivas. Tendo havido, no corpus de Santos (2006), crianças que produzem passivas estativas muito precocemente (TOM, 1 ano e 9 meses), julgamos poder estar implicado algo mais para além do domínio progressivo dos aspetos que caracterizam a estrutura passiva.

A aquisição desta estrutura parece estar relacionada à estrutura sintática subjacente a estas construções. Dada a existência de uma estrutura menos complexa associada à passiva estativa, tal poderá explicar a sua utilização mais frequente quando comparada com as passivas eventivas e resultativas. Estas diferenças poderão ter implicações na interpretação que as crianças fazem do contraste entre passivas eventivas, resultativas e estativas? ${ }^{7}$.

Para tentar explicar o número mais elevado de passivas estativas face às passivas eventivas e resultativas na fala das três crianças analisadas, há também que se considerar os dados do input, ou seja, as estruturas produzidas pelos adultos. A análise desses dados mostra que a percentagem de passivas estativas é incomparavelmente superior à de eventivas e resultativas. Estes dados parecem mostrar que as passivas estativas são mais frequentes na fala dirigida às crianças e são as estruturas mais ouvidas aquelas que mais precocemente são produzidas.

É relevante questionarmo-nos, neste ponto, sobre a quantidade de input que é necessária para que uma criança consiga estabelecer o parâmetro relevante para a aquisição da passiva na sua língua. A nossa amostra (três crianças) é reduzida e não temos disponíveis para o português europeu outros estudos sobre a aquisição da estrutura passiva que apresentem dados relativos a corpora de produção espontânea, pelo que uma análise nestes termos será certamente redutora. Contudo, relativamente ao inglês, Crawford (2012) argumenta que os estudos sobre a aquisição da passiva indicam que não é a frequência absoluta da passiva no input que vai determinar que o desempenho da criança seja próximo do do adulto. Exemplifica esta ideia afirmando que o bom desempenho que as crianças revelam perante passivas longas e passivas com verbos não agentivos, que são as mais raras no input, sugere que as crianças têm conhecimento de construções que são muito raras no input.

${ }^{7}$ Para uma descrição mais pormenorizada da tipologia tripartida de passivas e das representações sintáticas dos particípios eventivos, resultativos e estativos das frases, veja-se a proposta de Duarte e Oliveira (2010). 
Para além disso, há também evidência de que a aquisição de outras construções com ordem não canónica de constituintes (frases wh- com extração de objeto, como Who does Piggy wash?), não são afetadas pela reduzida ocorrência no input (HIRSCH; HARTMAN, 2006). Estes dados parecem sugerir que a baixa frequência de passivas no input não condiciona a sua aquisição.

Outro aspeto importante dos estudos de aquisição de passivas diz respeito à diferença entre passivas longas (com agente da passiva realizado) e curtas (sem agente da passiva realizado). No corpus de Santos (2006) não há qualquer registo de passivas longas na fala das crianças, nem no dos adultos. Essa ausência de passivas longas no input não condicionará a aquisição desta estrutura, sendo a criança capaz de interpretar o complemento agente da passiva, como mostra o estudo de Estrela (2013) para o português europeu.

Para além disso, é compreensível que não existam passivas longas, uma vez que as passivas representadas em maior número são as passivas estativas, precisamente aquelas que, à partida, não serão compatíveis com o complemento agente da passiva, porque não possuem nem eventividade nem agentividade.

\section{CONCLUSÃO}

Como vimos, os dados de produção mostram que antes dos dois anos há crianças que produzem passivas estativas, sendo as eventivas e as resultativas produzidas ainda antes dos três. Se as crianças conseguem produzir os três tipos de passivas, é certo que também as conseguem compreender, salvo se houver outros aspetos que possam estar interferindo em tal objetivo, quer sejam aspetos estritamente linguísticos, como os verbos implicados, quer sejam aspetos extralinguísticos.

A nossa proposta vai no sentido de mostrar que desde muito cedo as crianças conseguem produzir passivas estativas, surgindo os restantes tipos mais tarde, pelos motivos acima enunciados. Tratar-se-á, sobretudo, da simplicidade subjacente à estrutura estativa que permitirá a sua aquisição mais precocemente e também ao fato de ser geralmente produzida em situações que se relacionam com o próprio contexto.

Na nossa perspetiva, não é seguro afirmar que existe uma relação direta entre a quantidade de input recebido e as produções das crianças por dois motivos: em primeiro lugar, a criança que produziu menos passivas não é a que recebe menos passivas no input; em segundo lugar, necessitaríamos de uma quantidade muito superior de dados e de crianças participantes.

A verdade é que os dados de corpora mostraram-se fundamentais para análises deste tipo, em que se pretende verificar as estruturas produzidas por crianças em interação com os adultos. No entanto, o ideal será que exista uma complementaridade entre dados de corpora e dados de estudos experimentais para que se consiga alcançar os melhores resultados.

\section{REFERÊNCIAS}

CRAWFORD, J. Developmental perspectives on the acquisition of the passive. 2012. $258 \mathrm{f}$. Tese de Doutoramento. University of Connecticut. Disponível em: <http://alturl.com/te3up>. Acesso em: 3 set. 2015.

DEMUTH, K. Maturation and the acquisition of the sesotho passive. Language, v. 1, n. 65, p. 56-80, 1989.

DUARTE, I. Construções ativas, passivas, incoativas e médias. In: RAPOSO, E. B. P.; NASCIMENTO, M. F. B.; MOTA, M. A.; SEGURA, L.; MENDES, A. (Org.). Gramática do Português. Lisboa: Fundação Calouste Gulbenkian, 2013. p. 429-458.

DUARTE, I.; OLIVEIRA, F. Particípios resultativos. In: BRITO, A. M.; SILVA, F.; VELOSO, J.; FIÉIS, A. (Ed.). Textos seleccionados, XXV Encontro Nacional da Associação Portuguesa de Linguística. Porto: Associação Portuguesa de Linguística, 2010. p. 397-408.

EMBICK, D. On the structure of resultative participles in english. Linguistic Inquiry, v. 35, n. 3, p. 355-392, 2004. 
ESTRELA, A. A aquisição da estrutura passiva em Português Europeu. 2013. 285 f. Tese (Doutoramento em Linguística) - Faculdade de Ciências Sociais e Humanas, Universidade Nova de Lisboa, Lisboa, 2013.

GORDON, P.; CHAFETZ, G. Verb-based versus class-based accounts of actionality effects in children's comprehension of passives. Cognition, v. 36, p. 227-254, 1990.

HIRSCH, C.; HARTMAN, J. Some (wh-) questions concerning passive interactions. In: BELLETTI, A; BENNATI, E; CHESI, C.; DIDOMENICO, E.; FERRARI, I. (Ed.). Proceedings of the conference on generative approaches to language acquisition. Cambridge: Cambridge Scholars Press, 2006. p. 256-268.

ISRAEL, M., JOHNSON, C.; BROOKS, P. From states to events: the acquisition of english passive participles. Cognitive Linguistics, v. 11, n. 1/2, p. 103-30, 2000. Disponível em: <http://alturl.com/cyrmt>. Acesso em: 10 jun.2015.

KLINE, M.; DEMUTH, K. Factors facilitating implicit learning: the case of the Sesotho passive. Language Acquisition, v. 1, n. 17, p. 220-234, 2010. Disponível em: <http://www.mit.edu/ mekline/Papers/KlineDemuth2010_preprint.pdf>. Acesso em: 13 jul. 2015.

LIGHTFOOT, D. How to set parameters: arguments from language change. Cambridge, Mass.: MIT Press, 1991.

MACWHINNEY, B. The CHILDES Project: tools for analyzing talk. Hillsdale: Erlbaum, 2000.

O'BRIEN, K.; GROLLA, E.; LILLO-MARTIN, D. Long passives are understood by young children. In: BAMMAN, D.; MAGNITSKAIA, T.; ZALLER, C. (Ed.). Proceedings of the 30th Annual Boston University Conference on Language Development. Somerville: Cascadilla Press, 2006. p. 441-451.

SANTOS, A. L. Minimal Answers. Ellipsis, syntax and discourse in the acquisition of European Portuguese. $2006.296 \mathrm{f}$. Tese (Doutoramento) - Universidade de Lisboa, Lisboa, 2006.

YANG, C. Universal Grammar, statistics, or both? Trends in cognitive sciences, Oxford, v. 8, n. 10, p. 451-456, 2004. 